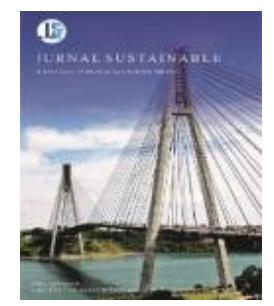

Jurnal Sustainable: Jurnal Hasil Penelitian dan Industri Terapan

Vol. 09, No. 02, hal. 94-102, Oktober 2020

Jurnal Sustainable: Jurnal Hasil Penelitian

dan Industri Terapan

ISSN 2615-6334 (Online)

ISSN 2087-5347 (Print)

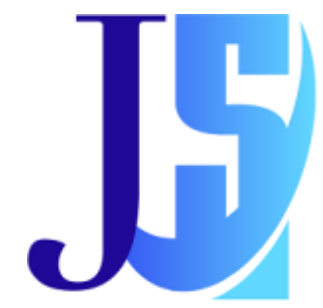

\title{
Rancang Bangun Toko Tambak Ikan (TOTAKAN)
}

\author{
Rusfa $^{1}$, Deny Nusyirwan ${ }^{2, *}$, Eko Prayetno $^{3}$, Bagas $^{4}$, Prasetya Perwira Putra Perdana ${ }^{5}$ \\ 1,4,5 Jurusan Teknik Elektro, Fakultas Teknik, Universitas Maritim Raja Ali Haji \\ ${ }^{2,3}$ Jurusan Teknik Perkapalan, Fakultas Teknik, Universitas Maritim Raja Ali Haji \\ $1,2,3,4,5 \mathrm{Jl}$. Politeknik Senggarang, Tanjungpinang 29100 \\ *Corresponding Author: denynusyirwan@umrah.ac.id
}

\begin{abstract}
The sale of fish is one of the main roles that is very important, in addition to getting the optimal price, the sale of fish is also very supportive of the economy of the region, especially the coast. In the sale of fish today still need a technological development in the field of calculation. The amount of fish and consumer demand makes fish sellers or fishermen unable to properly control the results of their sales, starting from service and pricing, calculation errors that cause prices to be not optimal, causing losses. Therefore, a solution is needed that can overcome these problems. TOTOKAN (Fish Pond Shop) is an innovation to prevent errors in the calculation of the selling price of fish using Arduino Uno-based RFID and LCD as its monitor. TOTAKAN is designed with an RFID system that has been programmed by ARDUINO UNO R3 which is a source of microproseor from all systems, while the $4 \times 4$ keypad serves as a calculation of the number of fish purchases as well as the overall price, and a 16x2 LCD serves to display the price and the number of copies. TOTAKAN is able to be the main solution for the regional economy, especially coastal areas. In addition to simple, this innovation can also create efficiency over time, so that the seller does not need to control the maximum sales results.
\end{abstract}

Keywords-efficiency, fish, innovation, error, loss, optimal

Intisari- Penjualan ikan menjadi salah satu peran utama yang sangat penting, selain untuk mendapatkan harga yang optimal, penjualan ikan yang terkoordinasi dengan baik juga sangat menunjang perekonomian daerah pesisir. Dalam penjualan ikan saat ini masih membutuhkan sebuah perkembangan teknologi di bidang perhitungan. Banyaknya ikan dan permintaan konsumen membuat para penjual ikan atau nelayan tidak dapat mengontrol dengan baik hasil penjualannya, mulai dari pelayanan maupun penetapan harga, kesalahan perhitungan yang menyebabkan harga menjadi tidak optimal sehingga menimbulkan kerugian. Oleh sebab itu, dibutuhkan sebuah solusi yang dapat mengatasi permasalah tersebut. TOTAKAN (Toko Tambak Ikan) merupakan inovasi pencegah kesalahan pada perhitungan harga penjualan ikan menggunakan RFID berbasis Arduino Uno dan LCD sebagai monitornya. TOTAKAN dirancang dengan sistem RFID yang telah diprogram oleh ARDUINO UNO R3 yang merupakan sumber mikroprosesor dari semua sistem, sedangkan keypad $4 \times 4$ berfungsi sebagai perhitungan jumlah pembelian ikan serta harga keseluruhannya, dan LCD 16x2 berfungsi untuk menampilan hasil harga beserta jumlah perkilonya. TOTAKAN ini mampu menjadi solusi utama untuk perekonomian daerah khususnya pesisir. Selain sederhana, inovasi ini juga dapat menciptakan efisiensi terhadap waktu, sehingga penjual tidak perlu mengontrol dengan maksimal hasil penjualannya.

Kata kunci- efisiensi, ikan, inovasi, kesalahan, kerugian, optimal 


\section{Pendahuluan}

Kebutuhan teknologi informasi saat ini sangat meningkat di berbagai sektor, sebagaimana yang diketahui bahwa teknologi perkembangannya begitu pesat. Kebutuhan masyarakat pesisir semakin meningkat menurut sumber dan data yang dihimpun pada berbagai daerah pesisir. Salah satu daerah yang berkawasan maritim menjadi sarana penting dalam perkembangan teknologi, kebutuhan ini didasarkan dalam aspek perekonomian daerah dan potensi wilayah yang harus dioptimalkan, dari segi perkembangan dan pertumbuhan. Penjualan ikan menjadi salah satu peran sektor yang sangat penting, selain untuk mendapatkan harga yang optimal, penjualan ikan juga sangat menunjang perekonomian daerah terkhusus pesisir. Dalam penjualan ikan saat ini masih membutuhkan sebuah teknologi untuk sebuah perhitungan, banyaknya ikan yang ingin dihitung harganya membuat para penjual ikan atau nelayan tidak dapat mengontrol harga menjadi optimal. Oleh sebab itu dinilai perlu untuk segera menemukan jalan keluar yang tepat agar permasalahan ini dapat diselesaikan. Solusi tersebut adalah TOTAKAN (Toko Tambak Ikan) menjual jenis ikan berdasarkan sistem kartu RFID menuju jual beli digital. Sangat memudahkan penjualan, karena efisien terhadap waktu dan optimal terhadap harga ikan. Menjadi solusi akurat untuk menunjang perekonomian nelayan, mencegah kesalahan, kecurangan, dan meningkatkan mutu penjualan.

\section{KaJian PUSTAKa}

Dalam pengerjaan penelitian ini, penulis telah terlebih dahulu melakukan kajian terhadap beberapa penelitian lain sebelumnya, hal tersebut akan gunakan sebagai batasan terhadap penelitian yang penulis lakukan, selain itu kajian pustaka juga menjelaskan mengenai purwarupa alat yang akan dirancang.

Penelitian dengan judul Kalkulator Digital Sederhana Sisi Kanan Mikrokontroler Arduino Uno menjelaskan tentang pemanfaataan teknologi era digital yang dapat membantu meningkatkan kinerja manusia secara efisiensi waktu dan penghematan biaya melalui sistem mikrokontroler. Dengan menggunakan kalkulator digital sederhana sisi kanan mikrokontroler Arduino uno yang berfungsi mengasah logika berfikir. Adapun komponen lain yang dipergunakan adalah keypad $4 \times 4$ dengan alat keluaran berupa LCD 16x2 dengan I2C dan Arduin uno R3 [1]

Selanjutnya Penelitian berjudul Penetapan Harga Jual Dengan Cost Plus Pricing Menggunakan Pendekatan Full Costing Pada Ud Gladys Bakery tentang pemanfaatan Gladys Bakery dan harga jual yang mengikuti harga pasar. Harga jual ini menggunakan metode Cost Plus Pricing menggunakan pendekatan Full Costing. Pendekatan Full Costing dipakai untuk menghitung harga jual sehingga harga jual yang dicapai perusahaan dapat bersaing dengan produk sejenis yang ada dipasaran.[2]

Penelitian berjudul Penghitung Jumlah Mobil Menggunakan Pengolahan Citra Digital Dengan Input Video Digital menjelaskan tentang bagaimana cara menghitung mobil dengan memanfaatkan webcam, yang bekerja pada masukan dalam bentuk video digital kemudian diolah dengan menggunakan pengolahan citra digital. Aplikasi ini dapat melakukan perhitungan terhadap dua mobil yang saling berjalan berdampingan dari arah yang berlawanan [3].

\section{Metode Penelitian}

Selama siklus proses perancangan rekayasa, rekayasawan diharapkan untuk sepenuhnya memahami kebutuhan pelanggan walaupun menghadapi tantangan berupa geografis, jadwal proyek yang sempit, atau anggaran yang pendek [4].

\section{Design Council Double Diamond}

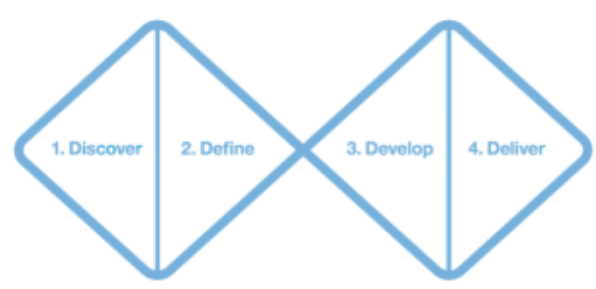

Gambar 1. Tahapan pada Proses Desain Rekayasa [5] 
Pada Gambar 1 menampilkan tahapantahapan dari Engineering Design Process (EDP) yang dilakukan oleh insinyur untuk menghasilkan inovasi, dimulai dengan identifikasi masalah. Dimulai dengan identifikasi masalah, dilanjutkan dengan curahan gagasan/ide yang dikenal dengan istilah brainstorming. Dalam tahapan ini, siswa akan diajak untuk berpikir secara luas tanpa perlu membatasi diri untuk bisa atau tidak membuat realisasi dari solusi yang diberikan. Luaran dari brainstorming akan di rancang dalam sketsa kertas dan dirakit bentuknya dengan mengguankan bahan-bahan sederhana. Hasil ahir dari solusi terhadap permasalahan ditunjukkan untuk memberikan informasi lengkap mengenai inovasi yang dihasilkan

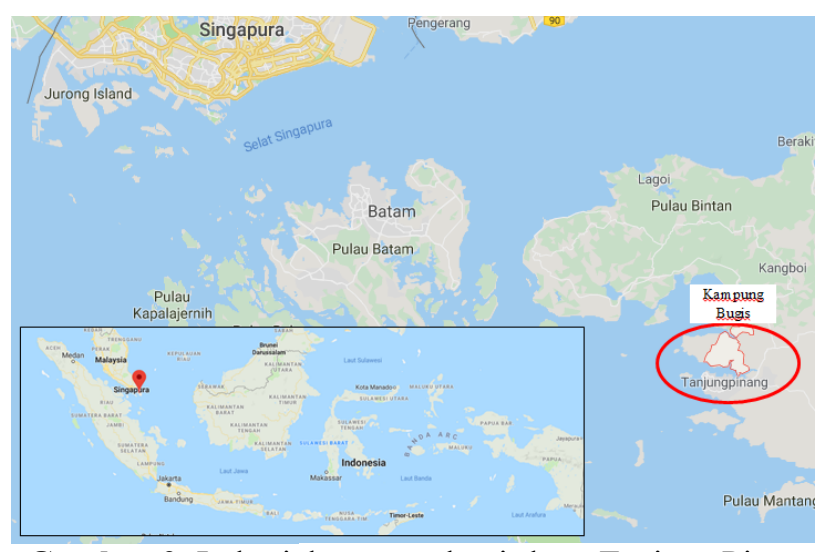

Gambar 2. Lokasi kampung bugis kota Tanjung Pinang [6]

Lokasi penelitian berada di Kecamatan Kampung Bugis Kelurahan Tanjungpinang Kota Kepulauan Riau pada sebuah komunitas nelayan, lihat Gambar 2.

Kampung Bugis adalah sebuah daerah yang teletak di pesisir kota Tanjungpinang dengan sebagian besar masyarakat memiliki mata pencaharian dari hasil laut. Kampung Bugis memiliki banyak potensi hasil tangkapan nelayan lokal, seperti ikan, udang, kepiting, dan tanaman laut yang bermanfaat. Menurut hasil observasi di Kampung Bugis, satu potensi tangkapan yang sangat besar dari yang sudah ada adalah Ikan. Ikan menjadi salah satu potensi yang sudah sangat umum dari berbagai wilayah di indonesia, namun untuk di kampung Bugis sendiri ikan telah menjadi salah satu potensi yang sangat dominan mendongkrak perekonomian mereka. Banyaknya ikan dan permintaan konsumen membuat para penjual ikan atau nelayan tidak dapat mengontrol dengan baik hasil penjualannya, mulai dari pelayanan maupun penetapan harga, kesalahan perhitungan yang menyebabkan harga menjadi tidak optimal sehingga menimbulkan kerugian. Oleh sebab itu, sebagai didorong dengan prinsip inovator yang selalu berfikir untuk membuat perubahan, dan perubahan itu adalah inovasi berbasis teknologi bernama TOTAKAN (Toko Tambak Ikan) yang merupakan inovasi pencegah kesalahan pada perhitungan harga penjualan ikan menggunakan RFID berbasis Arduino Uno dan LCD sebagai monitornya.

\section{Analisis Dan Pembahasan}

Keterampilan teknis yang dimiliki desainer perlu dilengkapi dengan kemampuan pendekatan yang lebih sistemik agar inovasi-inovasi baru dapat ditemukan dan memberikan manfaat ditengah masyarakat. Pada Gambar 3 memperlihatkan mahasiswa sebagai peneliti yang sedang berada di Kampung Nelayan, Kampung Bugis Kota Tanjungpinang untuk melakukan pendekatan sosial etnografi guna mengumpulkan informasi.

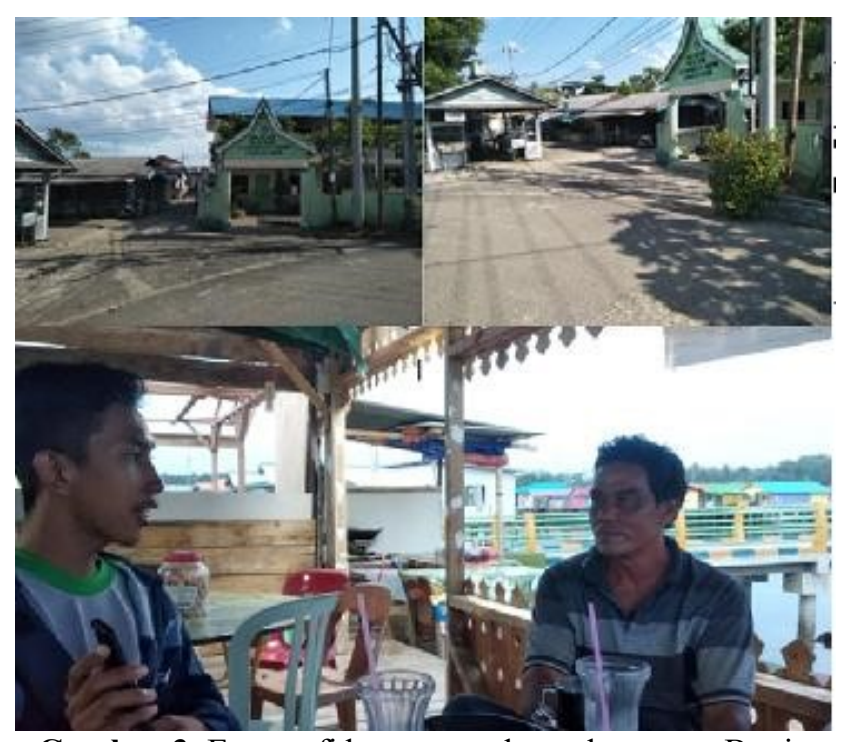

Gambar 3. Etnografi bersama nelayan kampung Bugis, kota Tanjungpinang

Tahapan selanjutnya adalah mengumpulkan informasi terkait permasalahan yang ditemukan 
ketika melakukan observasi etnografi di lokasi penelitian di Kampung Bugis. Informasi yang ditemukan dapat disampaikan dan ditulis dengan menggunakan media yang dapat dilihat. Adapun media yang pada umumnya dipergunakan adalah kertas post it.. Sila lihat pada Gambar 4

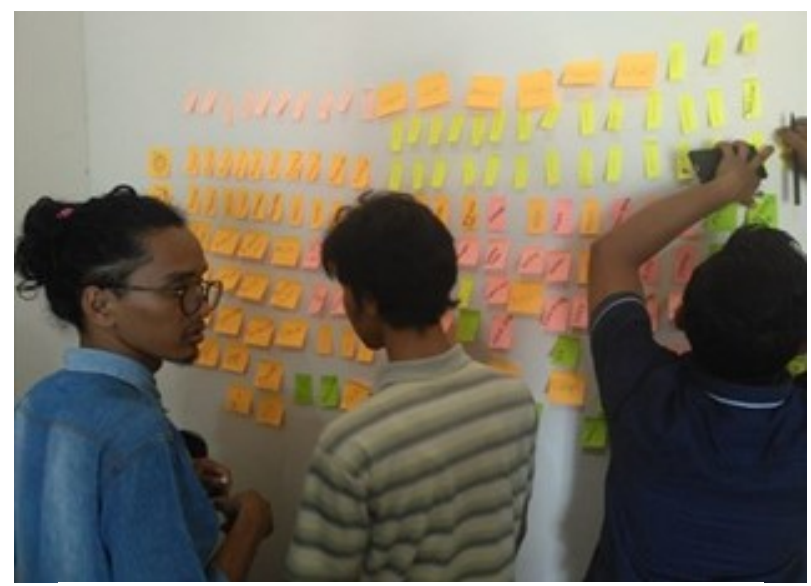

Gambar 4. Proses pengumpulan masalah-masalah

Upaya pengerucutan masalah dilakukan agar penelitian ini fokus pada satu titik, proses pengerucutan masalah dimulai dengan pengelompokan masalah ke dalam klasifikasi tertentu, dan selanjutnya di pilih satu masalah yang paling menonjol, lihat Gambar 5 . Berdasarkan hasil pengklasifikasian masalah tersebut, ditemukan bahwa permasalahan utama dari penelitian ini adalah kesalahan didalam meletakkan harga penjualan ikan ketika sedang melakukan transaksi penjualan.

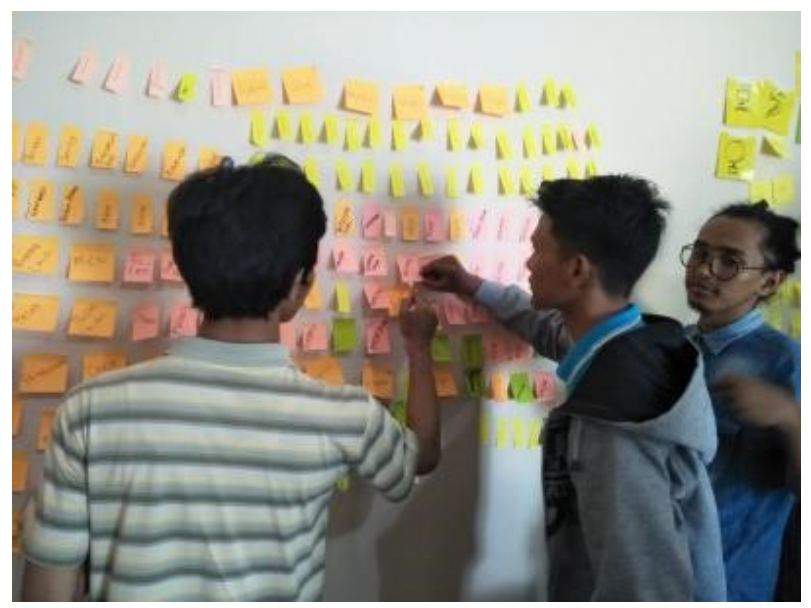

Gambar 5. Proses pengerucutan masalah

Selanjutnya bersama anggota lainnya menampilkan beberapa konsep solusi, sila lihat Gambar 6.

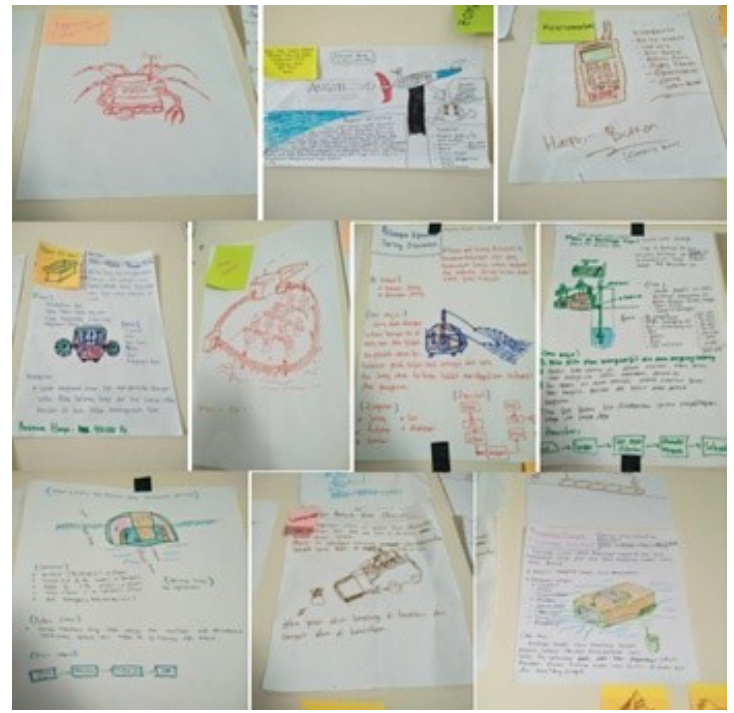

Gambar 6. Solusi terhadap permasalahan utama.

Berikutnya dicari beberapa alternatif solusi atas permasalahan utama tersebut, diantara alternatif solusi tersebut dipilihlah solusi dengan kriteria yang memiliki dampak signifikan jika diambil, dan solusi tersebut juga mampu menjawab tantangan kebutuhan masyarakat. Solusi utama yang didapat adalah membuat sebuah inovasi yang diberi nama TOTAKAN (Toko Tambak Ikan) dengan menerapkan penggunaan card tag rfid. Sila lihat Gambar 7.

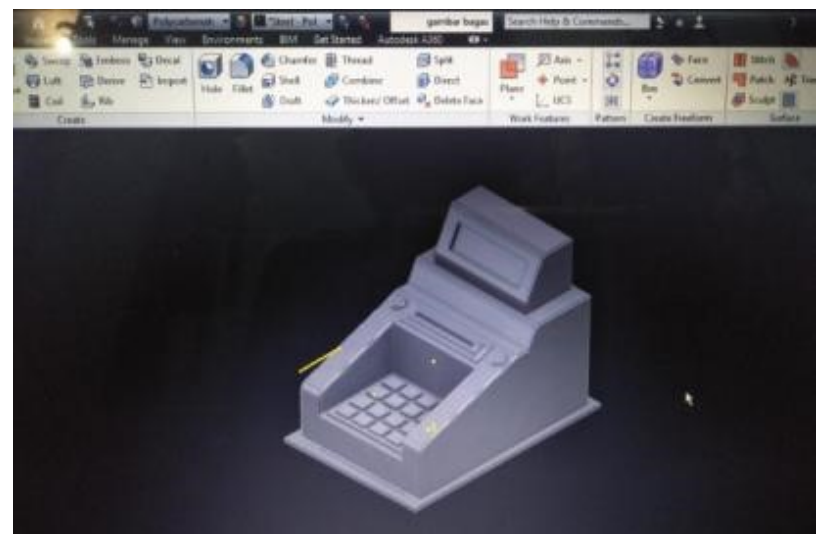

Gambar 7. Purwarupa virtual TOTAKAN

Selain itu, purwarupa juga dipergunakan sebagai media untuk komunikasi sesama anggota tim untuk mendapatkan gambaran jelas mengenai inovasi yang dimaksud dan alat bantu untuk mempelajari produk yang sudah ada sehingga pada akhirnya purwarupa memiliki kontribusi jelas untuk pengambilan keputusan didalam peluncuran produk di pasaran, sila lihat Gambar 8 


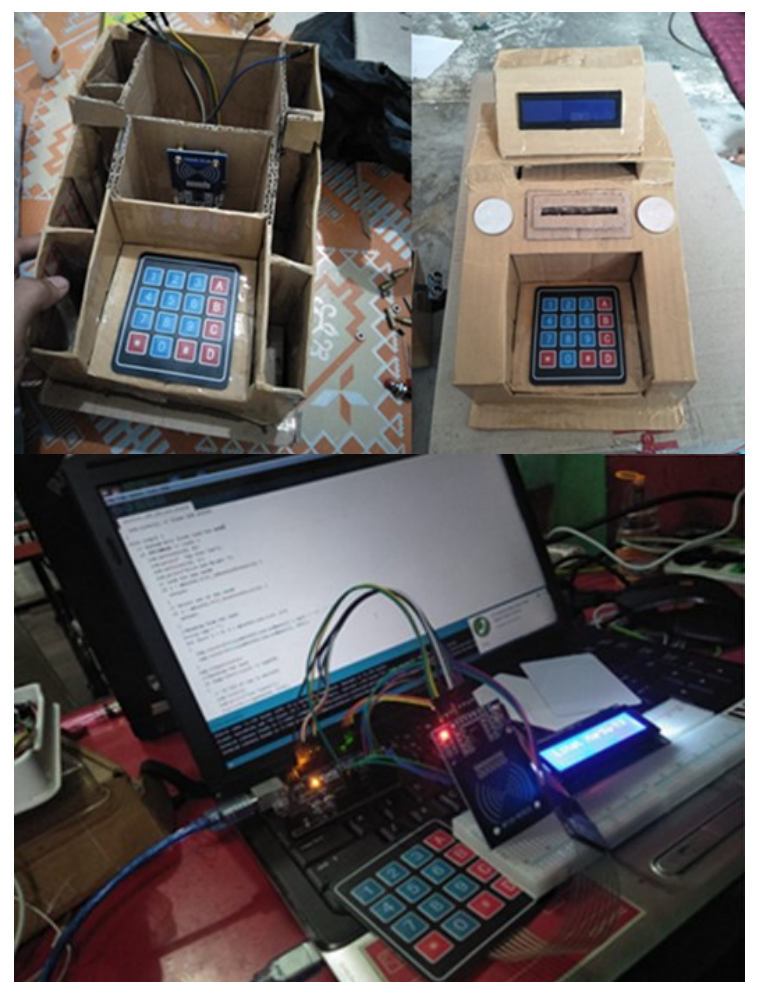

Gambar 8. Purwarupa TOTAKAN

Bangunan yang dirancang dengan baik akan mempengaruhi kehidupan masyarakat, dan situs web yang hasilkan dengan baik dapat mempengaruhi penjualan. Desain yang baik adalah bukan hanya terkait dengan tampilan, namun bagaimana menghasilkan perancangan yang berguna dan bermanfaat. Oleh sebab itu diperlukan pengujian kegunaan purwarupa TOTAKAN. Sila lihat Gambar 9.

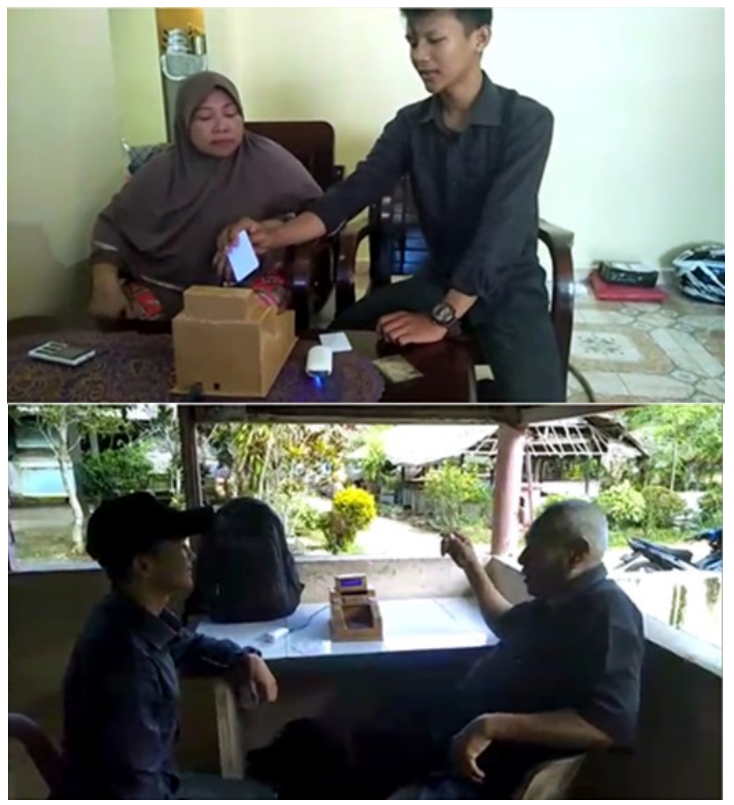

Gambar 9. Pengujian kegunaan bersama calon pengguna

Sebagaimana yang ditampilkan pada Tabel 1 dan Tabel 2, diperlihatkan informasi yang diperoleh dari hasil pengujian pengunan alat.

Tabel 1. Hasil Interview dari calon pengguna pertama

\begin{tabular}{|c|c|c|c|}
\hline No & Pertanyaan & $\begin{array}{l}\text { Jawaban } \\
\text { dan Alasan }\end{array}$ & Nilai \\
\hline 1 & $\begin{array}{l}\text { Apakah } \\
\text { purwarupa } \\
\text { mudah } \\
\text { digunakan? }\end{array}$ & $\begin{array}{l}\text { iya, sangat } \\
\text { mudah sekali }\end{array}$ & 90 \\
\hline 2 & $\begin{array}{l}\text { Apakah inovasi } \\
\text { ini menarik? }\end{array}$ & sangat bagus & 95 \\
\hline 3 & $\begin{array}{l}\text { Apakah inovasi } \\
\text { ini berguna di } \\
\text { lingkungan } \\
\text { masyarakat? }\end{array}$ & $\begin{array}{l}\text { iya, berguna } \\
\text { sekali }\end{array}$ & 85 \\
\hline 4 & $\begin{array}{l}\text { Apakah fungsi } \\
\text { dari inovasi ini } \\
\text { baik? }\end{array}$ & Baik & 80 \\
\hline 5 & $\begin{array}{lr}\text { Apakah } & \text { sistem } \\
\text { dalam } & \text { inovasi } \\
\text { ini } & \text { sudah } \\
\text { optimal ? } & \\
\end{array}$ & $\begin{array}{l}\text { sudah } \\
\text { optimal }\end{array}$ & 85 \\
\hline
\end{tabular}

Tabel 2. Hasil Interview dari calon pengguna kedua

\begin{tabular}{llll}
\hline No & Pertanyaan & $\begin{array}{l}\text { Jawaban } \\
\text { dan Alasan }\end{array}$ & Nilai \\
\hline & $\begin{array}{l}\text { Apakah } \\
\text { purwarupa ini } \\
\text { mudah } \\
\text { digunakan? }\end{array}$ & mudah sekali & 90 \\
\hline 2 & $\begin{array}{l}\text { Apakah inovasi } \\
\text { ini menarik? }\end{array}$ & Menarik & 80 \\
\hline & $\begin{array}{l}\text { Apakah inovasi } \\
\text { ini berguna di }\end{array}$ & iya, berguna & 85 \\
\hline & $\begin{array}{l}\text { lingkungan } \\
\text { masyarakat? }\end{array}$ & Apakah fungsi \\
dari inovasi ini & berfungsi \\
baik? dengan baik & 85 \\
\hline & $\begin{array}{l}\text { Apakah sistem } \\
\text { dalam inovasi } \\
\text { ini sudah } \\
\text { optimal sudah }\end{array}$ & 80 \\
\hline
\end{tabular}


Sistem kerja TOTAKAN menggunakan mikrokontroler arduino uno R3 berbasis RFID (Radio Frquency Identification) dan LCD sebagai penampil harga, TOTAKAN menggunakan keypad $4 \times 4$ untuk perhitungan harga penjualan yang diproses melalui arduino yang diinput melalui RFID card ketika tag RFID ditempelkan pada modul RFID READER. Sistem TOTAKAN ini juga dilengkapi dengan buzzer sebagai peringatan bahwa akses ID dari card tag RFID terbaca. Pada saat card tag RFID yang telah didaftarkan tersebut ditempelkan pada RFID READER maka Arduino akan memproses jenis ikan yang nantinya akan ditampilkan pada LCD. Misalkan ketika pelanggan memilih kartu jenis ikan tongkol, kemudian ditempelkan ke RFID maka LCD akan menampilkan jenis ikan dan harga ikan perkilonya, setelah itu pelanggan tinggal memilih berapa banyak ikan yang mau dibeli dengan menekan tombol keypad $4 \times 4$ tersebut, setelah itu Arduino akan memproses dan menampilkannya dilayar LCD, sila lihat

\section{Gambar 10.}

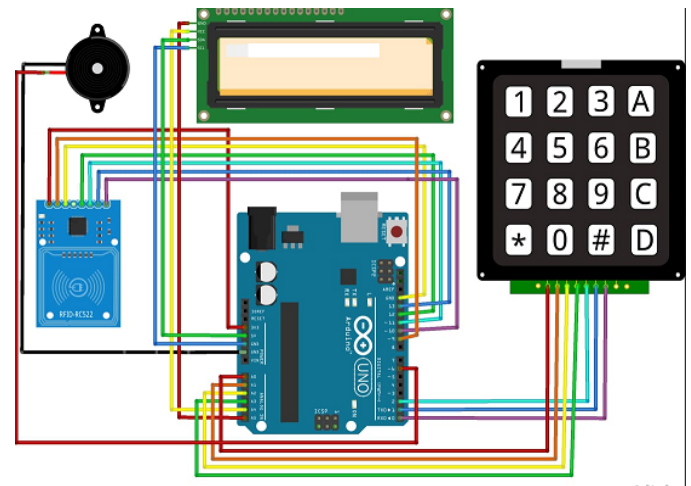

Gambar 10. Rangkaian Elektronika TOTAKAN

Adapun komponen peralatan yang dibutuhkan untuk membuat purwarupa beserta dengan estimasi harga dapat dilihat pada Tabel 3.

Tabel 3. Estimasi anggaran ( Bukalapak, diakses 09 Oktober 2020)

\begin{tabular}{lll}
\hline No & Nama Komponen & Harga (Rp) \\
\hline 1 & Arduino Uno R3 & $100.000,00$ \\
\hline 2 & LCD 16x2 & $19.500,00$ \\
\hline 3 & I2C LCD & $11.500,00$ \\
\hline 4 & RFID & $35.000,00$ \\
\hline 5 & Card RFID & $2.000,00$ \\
\hline 6 & Keypad 4x4 & $15.000,00$ \\
\hline 7 & Kabel Jamper & $6.000,00$ \\
\hline 8 & Papan Board & $25.000,00$ \\
\hline & Total & $219.000,00$ \\
\hline
\end{tabular}

Skematik diagram pada Toko Tambak Ikan ( TOTAKAN ) yang dipergunakan sebagai referensi untuk menyusun program pada mikrokontroler arduino uno, sila lihat Gambar 11.

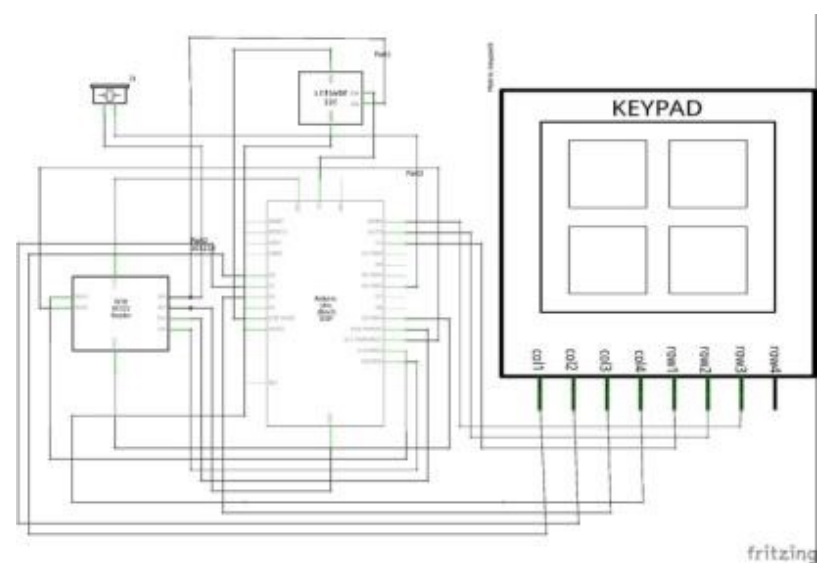

Gambar 11. Skematik diagram TOTAKAN

Setelah semua library dipanggil sesuai dengan perangkat yang dipergunakan pada purwarupa ini, yaitu Arduino UNO, RFID RC-522, LCD 16x2 I2C. maka dilakukan. Sila lihat Gambar 12.

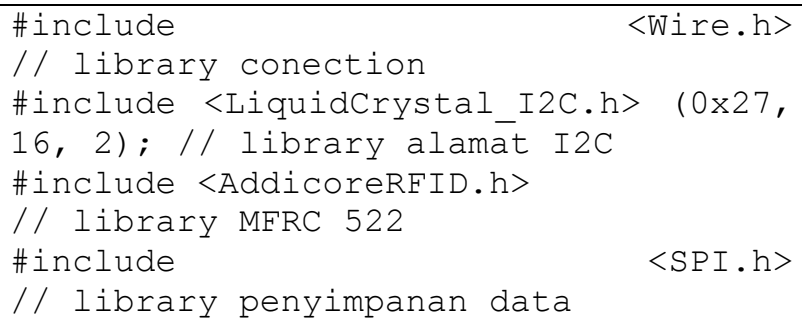

Gambar 18. inisialisasi dan input library

VOID SETUP untuk penempatan pin yang dipergunakan pada arduino agar arduino dapat membaca pin mana yang dipergunakan, lalu di fungsikan sebagai INPUT/OUTPUT. Untuk mengatur delay, dan arduino akan membaca 1 kali didalam program tersebut. Sila lihat Gambar 13. 


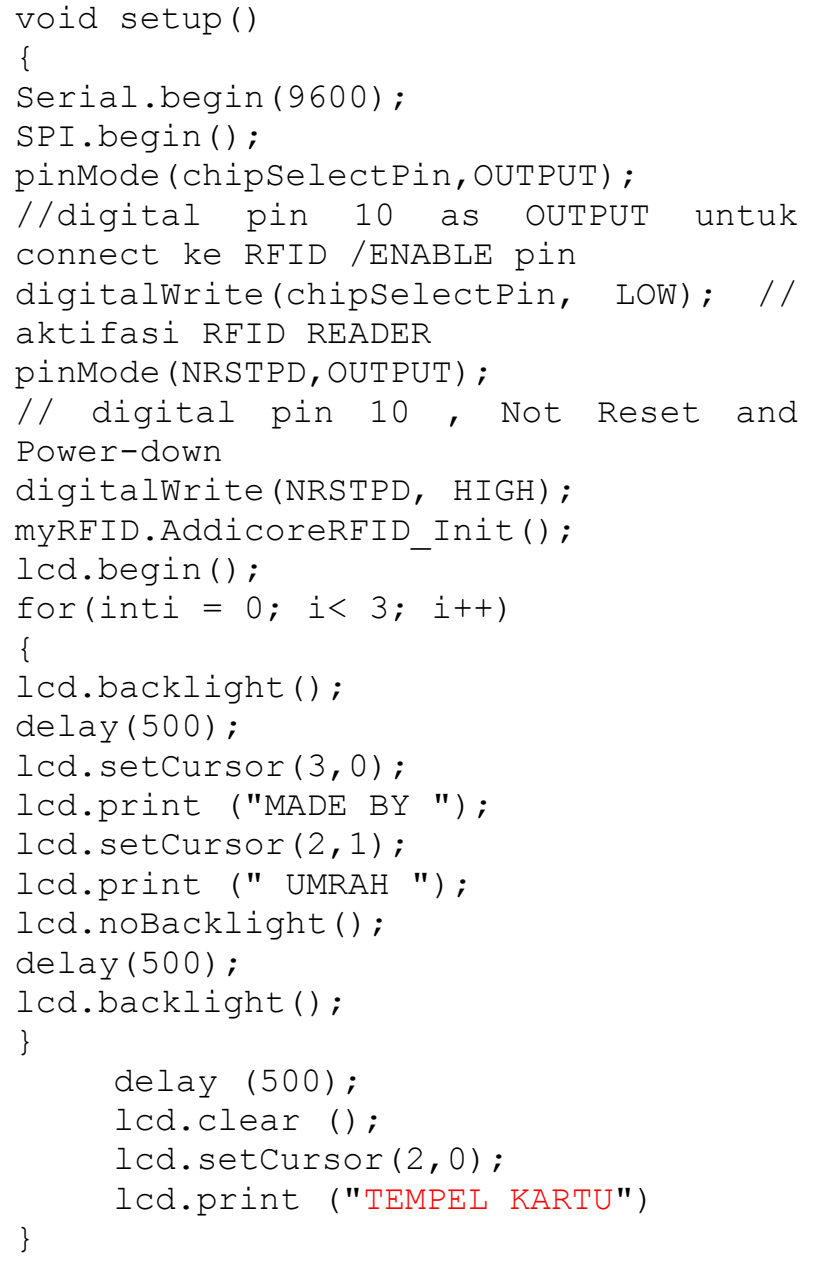

Gambar 13. void setup mengatur input dan output

Setelah itu dilanjutkan ke void loop, adapun fungsi dari void loop adalah sebagai perulangan dalam program, artinya semua kode yang diletakan dalam void loop ini akan dibaca berulang kali dan terus menerus oleh arduino. Void loop pada program ini berfungsi untuk menampilkan perulangan dan juga untuk mengatur text serial printing yang di munculkan di LCD 16x2

Pada program ini terdapat 4 permisalan IF, karna menggunakan 4 kartu, kartu pertama untuk menampilkan nama ikan (ikan kerapu), kartu kedua (ikan tamban), kartu ketiga (ikan bilis), dan kartu keempat (ikan kakap). Dan begitulah cara program dari studi ini, jika kartu ditempelkan, maka pada LCD akan muncul teks monitor nama ikan sesuai dari kartu yang ditempelkan dan telah di program. Sila lihat Gambar 14.

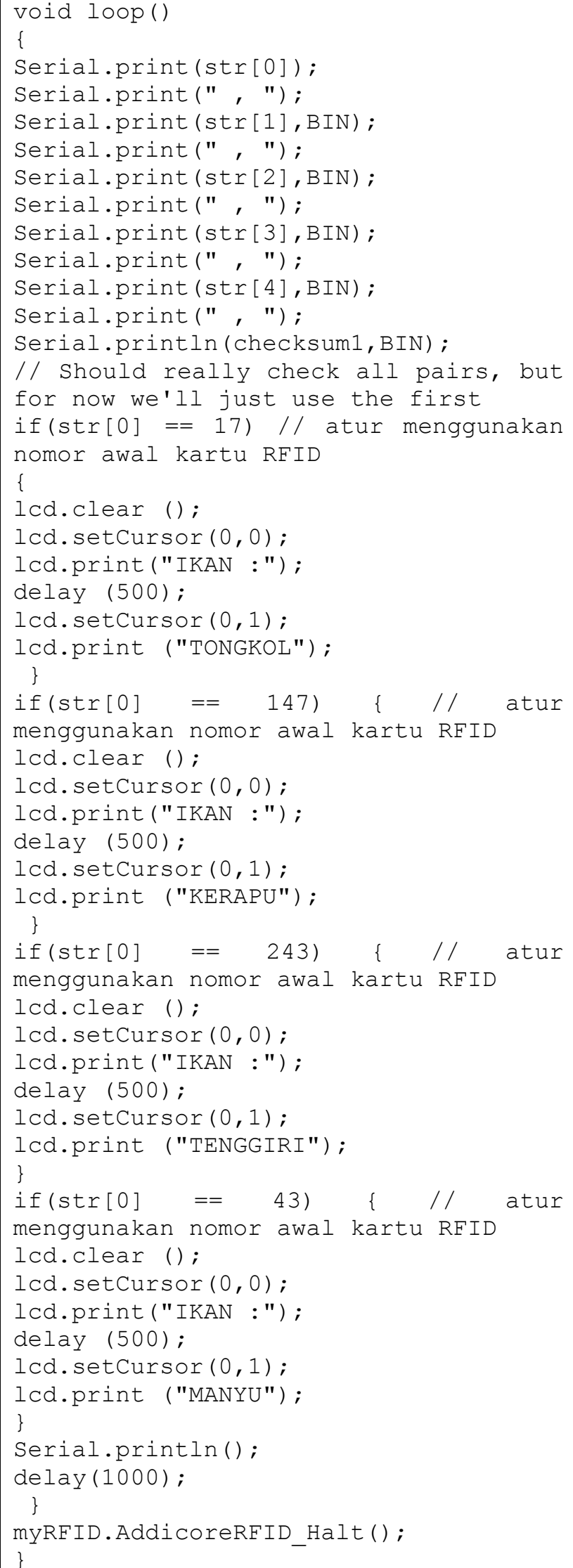


Gambar 20. void loop mengatur fungi perulangan

\section{KeSIMPUlan Dan SARAN}

Dalam penjualan ikan saat ini masih membutuhkan sebuah teknologi untuk melakukan perhitungan, banyaknya ikan yang ingin dihitung harganya membuat para penjual ikan atau nelayan tidak dapat mengetahui harga menjadi optimal. Oleh sebab itu dibutuhkan solusi yang memanfaatkan teknologi terbaru, yang mampu mengatasi permasalahan tersebut, yaitu TOTAKAN (Toko Tambak Ikan), purwarupa berbasis mikrokontroler untuk perhitungan penjualan jenis ikan berdasarkan sistem kartu RFID.

Sistem kerja TOTAKAN menggunakan mikrokontroler arduino uno R3 berbasis RFID (Radio Frequency Identification) dan LCD sebagai penampil harga, TOTAKAN menggunakan keypad 4x4 untuk perhitungan harga penjualan yang diproses melalui arduino yang diinput melalui RFID card ketika tag RFID ditempelkan pada modul RFID READER. Sistem TOTAKAN ini juga dilengkapi dengan buzzer sebagai peringatan bahwa akses ID dari card tag RFID terbaca.

Berdasarkan hasil pengujian purwarupa bersama calon pengguna inovasi di kampung nelayan Kampung Bugis, diperoleh informasi bahwa inovasi yang dihasilkan mudah dipergunakan. Sistem yang diujicoba juga telah dapat berfungsi dengan baik.

Dari hasil pengujian bersama calon pengguna yang memuaskan tersebut, maka dapat disimpulkan juga bahwa proses perancangan rekayasa untuk menghasilkan sebuah inovasi, memerlukan sebuah pendekatan secara sosial dengan cara interaksi langsung bersama calon pengguna inovasi selama proses perancangan, yang diintegrasikan dengan pola pikir secara luas untuk dapat menemukan permasalahan utama yang selanjutnya menjadi tujuan untuk dapat menghasilkan inovasi berbasis teknologi yang bermanfaat bagi calon pengguna tersebut.

Wilayah Provinsi Kepulauan Riau memiliki wilayah lautan lebih luas dari daratan. Selain itu, berbatasan dengan negara tetangga Singapura dan Malaysia. Dengan alasan tersebut pentingnya penguasaan teknologi bagi masyarakat pesisir untuk mampu mempercepat proses jual beli ikan. Perguruan tinggi sebagai pusat inovasi memerlukan kerjasama dengan pemerintah daerah untuk dapat mendesiminasikan hasil penelitian. Dengan demikian akan terjadi percepatan penguasaan teknologi di daerah pesisir, sehingga mampu meningkatkan ketahanan negara Indonesia kedepannya.

\section{UCAPAN TERIMA KASIH}

Terima kasih penulis ucapkan kepada seluruh civitas akademika di Fakultas Teknik Universitas Maritim Raja Ali Haji (UMRAH).

\section{Daftar Pustaka}

[1] N. Rohkhim, B. Laksono Aji, dan S. Winardi, Kalkulator Digital Sederhana Sisi Kanan MikrokontrolerArduino Uno, Researchgate, 2019

[2] C. Moray, D. P. E. Saerang, dan T. Runtu, Penetapan Harga Jual Dengan Cost Plus Pricing Menggunakan Pendekatan Full Costing Pada Ud Gladys Bakery, Jurnal Riset EMBA UNSRAT, Vol. 2, No. 2, hlm. 1272-1283, 2014.

[3] M. Aynurrohmah dan A. Sunyoto, Penghitung Jumlah Mobil Menggunakan Pengolahan Citra Digital Dengan Input Video Digital, Jurnal DASI, Vol. 12, No. 3, 2011

[4] J. C. Pereira, and R. F.S.M. Russo, Design Thinking Integrated In Agile Software Development: A Systematic Literature Review, Procedia Computer Science, Vol. 138, hlm. 775-782, 2018.

[5] Double Diamand [Daring],Tersedia pada : http://www.openchange.co.uk/the-doublediamond [ Diakses : 09 Oktober 2020 ].

[6] Kp. Bugis Tanjungpinang Kota, Kota Tanjung Pinang, Kepulauan Riau [Daring],Tersedia pada : https://maps.app.goo.gl/hpUcUX5Qy9drfJx g7 [ Diakses : 09 Oktober 2020 ]. 
Rusfa, D. Nusyirwan, E. Prayetno, Bagas, P. P. P. Perdana, Rancang Bangun Toko Tambak Ikan (TOTAKAN) 